Abstract 0-137 Table 1

\begin{tabular}{|c|c|c|c|c|c|c|c|}
\hline Study & $\begin{array}{l}\text { Eligible for } \\
\text { discussion with } \\
\text { parents (N) }\end{array}$ & Approached (N) & Consented (N) & Consent rate $(\%)$ & Time for screening (min) & Time for discussion (min) & $\begin{array}{l}\text { Mean time spent on screening } \\
\text { and discussions for each } \\
\text { consent participant (min) }\end{array}$ \\
\hline A & 97 & 75 & 72 & 95 & 20 & 30 & 58 \\
\hline B & 250 & 183 & 134 & 73 & 20 & 30 & 78 \\
\hline C & 261 & 99 & 10 & 10 & 30 & 45 & 1228 \\
\hline
\end{tabular}

talking about their pain; they felt that such would work best on a one-to-one basis or in small groups. They provided feedback on where we should position ourselves in ward settings whilst undertaking non-participant observation of children during the post-operative period. They made practical suggestions about how children could assent and withdraw from the study.

Conclusions From our experience our consultations were invaluable and worth the effort; our final design was more robust and grounded in the children's realities.

\section{0-137 SCREENING AND RECRUITMENT TO CLINICAL STUDIES ON A REGIONAL NEONATAL UNIT: A COMPARISON OF THREE STUDIES WITH CONTRASTING CHARACTERISTICS}

${ }^{1} \mathrm{P}$ McGowan, ${ }^{1} \mathrm{~J}$ Windrow, ${ }^{1} \mathrm{~K}$ Harvey, ${ }^{1} \mathrm{~B}$ Howell, ${ }^{2} \mathrm{MA}$ Turner. ${ }^{1}$ Neonatal Unit, Liverpool Women's NHS FT, Liverpool, UK; ' Women's and Children's Health, University of Liverpool, Liverpool, UK

\subsection{6/archdischild-2014-307384.204}

Introduction The resources required to recruit neonatal studies are thought to be greater than for other studies but have not been formally described to date. The aim of this report is to summarise our experience of the effort required to recruit neonates to studies and our success rate with recruitment.

Methods Three contrasting studies were selected from our portfolio. The numbers of babies that were eligible, approached and consented were extracted from our screening logs. The rate of consent among families who were approached was calculated. The time taken for each step was assessed for a selection of families and scaled up for the whole study.

Results Study A was a non-interventional study requiring daily faecal samples. Study B involved taking dried blood spots for pharmacokinetic assays of medication used as routine clinical practice. Study C was a first-in-human study of a novel medicine. Key metrics are summarised in the Table.

The total times spent do not reflect time spent looking for parents or staff.

Discussion Recruitment to neonatal clinical studies requires considerable time, effort and teamwork. The consent rate differs according to the intensity of the study. Funders should take account of screening and recruitment times.

\section{Nursing Team and Parenting}

\section{0-138 THE IMPACT OF PARENTING STYLE ON JORDANIAN ADOLESCENTS' WELL-BEING IN THE NORTH OF JORDAN}

A Al-Anati. Community and Mental Health, Jordan University of Science and Technology, Irbid, Jordan

10.1136/archdischild-2014-307384.205
Background and aims Parenting is a complex activity includes specific practices that affect on adolescents 'development. This study aimed to describe the types of parenting styles among Jordanian adolescents in the north of Jordan. As well as, to examine the relationship between parenting style and adolescents' well-being (general mental health, self - esteem, and schools' achievement.

Methods A cross sectional design was used to collect data from 500 students in the age of 13-16 years old (8th, 9th, 10th) classes in the period between April and May, 2012. Parenting Authority Questioner (Buri, 1991), General Health Questioner (Golderberg, 1988), Hare self-esteem scale (Hare, 1985) were used in this study. Clusters random sample was used to select the elements from public and private schools of the three educational directorates of Irbid Governorate.

Results 222 (44.4\%) male, and 278(55.6\%) female students participated in this study. The results of this study showed the means of authoritative parenting style was 35.3 ( $\mathrm{Sd}=5.7$ ), authoritarian style was $31.6(\mathrm{Sd}=4.1)$, and permissive parenting style was $(\mathrm{Sd}=4.6)$ (33.3) with scale range $=10-50)$. The results showed a negative correlation between three types of parenting styles, and adolescents mental health. A positive correlation found between the three types of parenting styles, and adolescents' self-esteem. However, there was significant differences between three types of parenting styles, and adolescents GPA.

Conclusion Jordanian parenting styles had positive impact on adolescents' self-esteem, and academic achievements, while, it had negative impact on adolescents' mental health.

\section{0-139 GIVING VOICE TO THE EXPERIENCES OF FIRST-TIME FATHERS OF LATE PRETERM INFANTS: A QUALITATIVE STUDY}

${ }^{1} \mathrm{~K}$ Benzies, ${ }^{2} \mathrm{~J}$ Magill-Evans. ${ }^{1}$ Faculty of Nursing, University of Calgary, Calgary, Canada; ${ }^{2}$ Faculty of Rehabilitation Medicine, University of Alberta, Edmonton, Canada

\subsection{6/archdischild-2014-307384.206}

The transition to fatherhood can generate a range of cognitive and emotional experiences. The purpose of this study was to explore the experiences of first-time fathers of late preterm (34 to 36 weeks gestation) infants. The study was part of a larger randomised controlled trial to test a video-modelled play intervention for fathers that was delivered during home visits. At the outcome home visit ( 8 months corrected age) we used structured interviews with 85 fathers to explore the joys and challenges of fathering a late preterm infant. The interviews were transcribed and analysed using a thematic approach. Three main themes about fathers' experiences emerged. Fathers believed that spending time with the baby, watching the baby grow and learn, and being recognised by the baby contributed to fathering being the "best job in the world." Specific concerns about keeping the baby safe, meeting developmental milestones, self-confidence in 